\title{
Rapid Consolidation to a radish and Protein Synthesis- Dependent Long-Term Memory after Single-Session Appetitive Olfactory Conditioning in Drosophila
}

\author{
Michael J. Krashes and Scott Waddell \\ Department of Neurobiology, University of Massachusetts Medical School, Worcester, Massachusetts 01605
}

In Drosophila, formation of aversive olfactory long-term memory (LTM) requires multiple training sessions pairing odor and electric shock punishment with rest intervals. In contrast, here we show that a single 2 min training session pairing odor with a more ethologically relevant sugar reinforcement forms long-term appetitive memory that lasts for days. Appetitive LTM has some mechanistic similarity to aversive LTM in that it can be disrupted by cycloheximide, the dCreb2-b transcriptional repressor, and the crammer and tequila LTMspecific mutations. However, appetitive LTM is completely disrupted by the radish mutation that apparently represents a distinct mechanistic phase of consolidated aversive memory. Furthermore, appetitive LTM requires activity in the dorsal paired medial neuron and mushroom body $\alpha^{\prime} \beta^{\prime}$ neuron circuit during the first hour after training and mushroom body $\alpha \beta$ neuron output during retrieval, suggesting that appetitive middle-term memory and LTM are mechanistically linked. Last, experiments feeding and/or starving flies after training reveals a critical motivational drive that enables appetitive LTM retrieval.

Key words: memory formation; consolidation; olfactory; Drosophila; mechanisms; circuits

\section{Introduction}

Studies in humans and several animal models have demonstrated that multiple training trials with rest intervals (spaced training) is most effective in producing long-term memory (LTM) (Ebbinghaus, 1885; Carew et al., 1972; Frost et al., 1985; Tully et al., 1994). A single trial, or even multiple training trials without rest intervals (massed training), usually only forms robust short-term memory (STM). However, there are some notable exceptions that indicate that spaced training is not always essential to form LTM. In conditioned taste aversion learning in rodents (and pond snails), a single exposure of a tastant, followed by malaise (or salt exposure), leads to a long-lasting avoidance of the associated taste (Garcia et al., 1955; Sugai et al., 2007). Similarly, in the passive avoidance task in chicks, one peck at a bitter-tasting colored bead leads to avoidance of a bead of that color for days (Lossner and Rose, 1983). Long-lasting memories formed by a single trial can also be appetitive. In rodents, LTM for taste preference can be formed if presentation of a tastant is followed by an injection of a nutritional supplement (Garcia et al., 1967). Furthermore, a single trial of conditioning pairing odorant/tastant and sucrose in the pond snail forms an appetitive LTM for that odorant/tastant (Fulton et al., 2005). Last, a single trial of appetitive conditioning forms a protein synthesis-independent long-

Received Dec. 1, 2007; revised Feb. 5, 2008; accepted Feb. 5, 2008.

This work was supported by National Institutes of Health Grant MH09883 to S.W. We thank Motojiro Yoshihara and Jena Pitman for critical comments on this manuscript and Jerry Yin, Thomas Preat, Ron Davis, and Josh Dubnau for fly strains.

Correspondence should be addressed to Dr. Scott Waddell, Department of Neurobiology, University of Massachusetts Medical School, 364 Plantation Street, Worcester, MA 01605. E-mail: scott.waddell@umassmed.edu. DOI:10.1523/JNEUROSCI.5333-07.2008

Copyright $\odot 2008$ Society for Neuroscience $\quad$ 0270-6474/08/283103-11\$15.00/0 lasting memory in honeybees (Menzel, 2001). The common factor in these five cases is the involvement of gustation and feeding behavior suggesting that fast acquisition of stable memory may be a conserved feature of feeding-related learning.

In Drosophila, formation of aversive LTM requires 5-10 spaced training trials, pairing odor with punitive shock, with 15 min rest intervals (Tully et al., 1994). Flies can also be trained with odor and a more ethologically relevant sucrose reward (Tempel et al., 1983; Schwaerzel et al., 2003, 2007; Keene et al., 2006; Kim et al., 2007), and even in the first report, it was noted that memory after two trials of appetitive conditioning persisted longer than that after two trials of aversive conditioning (Tempel et al., 1983). We therefore sought to determine whether appetitive olfactory conditioning could form LTM and whether appetitive LTM formation shared rules and mechanisms with that of aversive LTM. There are a number of reasons to favor an appetitive protocol. First, sugar is a salient stimulus to the fly because it represents food. Second, the gustatory receptors that sense sucrose (Dahanukar et al., 2007; Jiao et al., 2007; Slone et al., 2007), and the receptor neurons that express these receptors (Thorne et al., 2004; Wang et al., 2004; Marella et al., 2006), are well described giving us instant access to unconditioned stimulus processing and the neural circuits delivering that information to deeper layers of the brain. Last, appetitive memory formation and retrieval requires motivation because only hungry flies display learned behavior (Tempel et al., 1983; present study).

\section{Materials and Methods}

Flies. Fly stocks were raised on standard cornmeal food at $25^{\circ} \mathrm{C}$ and $60 \%$ relative humidity. The wild-type Drosophila strain used in this study was Canton-S. The flies harboring the heat-shock-inducible $h s-d C r e b 2-b$ re- 
pressor transgene are those described as 17-2 (Yin et al., 1994). Flies harboring the uas- $d C r e b 2-b$ repressor transgene on the second chromosome were described previously (Yu et al., 2006). We expressed dCreb2-b in the mushroom bodies (MBs) by crossing female flies harboring the uas- $d C r e b 2-b$ repressor transgene to male flies containing the $c 739$ GAL4, c772-GAL4, and MB247-GAL4 driver insertions (Zars et al., 2000; McGuire et al., 2001). All resultant c739-GAL4; uas-dCreb2-b, c772GAL4/uas- $d C r e b 2-b$, and uas- $d C r e b 2-b$;MB247-GAL4 flies are heterozygous for each transgene. Heterozygote control uas- $d$ Creb2-b/+, c739/+, $\mathrm{c} 772 /+$, and MB247/+ flies were generated by crossing wild-type female flies to uas- $d$ Creb2- $b$, c739, c772, and MB247 male flies. Mutant radish $(r s h)$, crammer $\left(\operatorname{cer}^{P}\right)$, and tequila $\left(\right.$ teq $\left.^{\text {fol }}{ }^{1792}\right)$ strains are those described previously (Folkers et al., 1993; Comas et al., 2004; Didelot et al., 2006). We used flies carrying a single insertion of the uas-shit ${ }^{\text {tsl }}$ transgene (Kitamoto, 2001) on the third chromosome. We previously described the dorsal paired medial (DPM) neuron-expressing c316-GAL4 (Waddell et al., 2000) and Mz717-GAL4 (Keene et al., 2004) drivers. The c739-GAL4 that expresses in the $\mathrm{MB} \alpha \beta$ lobes and the $305 \mathrm{a}-\mathrm{GAL} 4$ line that primarily expresses in the $\mathrm{MB} \alpha^{\prime} \beta^{\prime}$ lobes were described previously (McGuire et al., 2001; Krashes et al., 2007). The c547, Ruslan, and Feb170 GAL4 lines that express in ellipsoid body (EB) ring neurons were described previously (Renn et al., 1999; Wu et al., 2007). We generated c305a-GAL4; uas-shi ${ }^{\text {ts } 1}$, c739-GAL4; uas-shit ${ }^{\text {ts1 }}$, c316-GAL4/uas-shit ${ }^{\text {ts1 }}$, Mz717-GAL4/uas-shit ${ }^{\text {ts } 1}$, c547-GAL4; uas-shi ${ }^{\text {ts1 }}$, Ruslan-GAL4; uas-shi ${ }^{\text {ts1 }}$, and Feb170-GAL4;uas$s h i^{\text {ts1 }}$ flies by crossing uas-shit ${ }^{\text {ts } 1}$ females to c305a, c739, c316, Mz717, c547, Ruslan, and Feb170 male flies. Heterozygote control uas-shitsl $/+$, c305a/+, c739/+, c316/+, Mz717/+, c547/+, Ruslan/+, and Feb170/+ flies were generated by crossing wild-type females to uas-shi ${ }^{\text {ts1 }}, \mathrm{c} 305 \mathrm{a}$, c739, c316, Mz717, c547, Ruslan, and Feb170 male flies. All flies tested are heterozygote for the listed transgenes, and a mixed population of sexes were assayed, except for Feb170-GAL4; uas-shi ${ }^{\text {ts }}$, in which only females were tested because Feb170 is on the X-chromosome.

Cycloheximide feeding, heat-shock, and cold-shock anesthesia protocols. Wild-type flies were food deprived at $25^{\circ} \mathrm{C}$ for $16 \mathrm{~h}$ in milk bottles containing one $10 \times 6 \mathrm{~cm}$ Whatmann $3 \mathrm{MM}$ filter paper soaked with $3 \%$ ethanol solution or $35 \mathrm{~mm}$ cycloheximide (CXM) in $3 \%$ ethanol. Flies were then transferred to milk bottles containing one $10 \times 6 \mathrm{~cm}$ Whatmann $3 \mathrm{MM}$ filter paper soaked with water and given $1 \mathrm{~h}$ to recover before training. Previous experiments determined that a $12-15$ h CXM exposure before olfactory conditioning attenuates $24 \mathrm{~h}$ memory performance after an aversive spaced training protocol (Tully et al., 1994).

We induced expression of the hs- $d$ Creb2- $b$ transgene with heat shock using a variation of the previously published protocol (Yin et al., 1994). After $14-16 \mathrm{~h}$ of food deprivation, flies were transferred to $37^{\circ} \mathrm{C}$ preheated milk bottles and incubated in a $37^{\circ} \mathrm{C}$ incubator for $30 \mathrm{~min}$. Flies were then transferred back to milk bottles at room temperature containing one $8 \times 3 \mathrm{~cm}$ Whatmann $3 \mathrm{MM}$ filter paper soaked with water and given $2 \mathrm{~h}$ to recover before training.

Cold-shock anesthesia was delivered as described previously (Folkers et al., 1993). Briefly, flies were transferred to prechilled plastic vials $1 \mathrm{~h}$ before, immediately after, $2 \mathrm{~h}$ after, or $12 \mathrm{~h}$ after training, and the vials were put in a $4^{\circ} \mathrm{C}$ ice bucket for $2 \mathrm{~min}$. Locomotor activity ceased immediately. Flies were allowed to recover by transferring them to roomtemperature vials containing a water-dampened filter paper. They started moving within $30 \mathrm{~s}$ and were stored at $25^{\circ} \mathrm{C}$ until testing.

Behavioral analyses. The olfactory appetitive conditioning paradigm was performed as described previously (Keene et al., 2006; Krashes et al., 2007). Flies were food deprived for $16-20 \mathrm{~h}$ before conditioning in milk bottles containing a $10 \times 6 \mathrm{~cm}$ Whatmann $3 \mathrm{MM}$ filter paper soaked with water. The training tube [positive conditioned stimulus $(\mathrm{CS}+)$ ] contains a filter paper with dried sucrose that covers the entire wall of the training tube. The filter paper was made by applying a saturated sucrose solution and allowing it to dry before use. Another tube (CS-) was prepared with a filter paper that was soaked in water (and allowed to dry). Conditioning was performed as follows: $\sim 100$ starved flies were loaded into the elevator section of a T-maze. Flies were transferred to the CS - tube, and odor was delivered for $2 \mathrm{~min}$. After $30 \mathrm{~s}$ of clean air stream, they were transferred back into the elevator and then into the (CS+) tube containing sugar reinforcement in the presence of another odor for 2 min. Memory
Table 1. Olfactory acuity and sucrose acuity for strains used in this study

\begin{tabular}{|c|c|c|c|c|c|c|}
\hline \multirow[b]{2}{*}{ Strain } & \multicolumn{4}{|c|}{ Odor acuity } & \multirow{2}{*}{$\begin{array}{l}\text { Sucrose } \\
\text { acuity }\end{array}$} & \multirow[b]{2}{*}{ SEM } \\
\hline & OCT & SEM & MCH & SEM & & \\
\hline Wild-type & 0.56 & 0.06 & 0.63 & 0.06 & & \\
\hline uas- $d(r e b 2-b /+$ & 0.50 & 0.01 & 0.59 & 0.04 & & \\
\hline$c 739 /+$ & 0.51 & 0.02 & 0.54 & 0.05 & & \\
\hline c739;uas-dCreb2-b & 0.57 & 0.03 & 0.58 & 0.04 & & \\
\hline MB247/+ & 0.52 & 0.06 & 0.57 & 0.05 & & \\
\hline MB247/uas-dCreb2-b & 0.53 & 0.04 & 0.61 & 0.03 & & \\
\hline c772/+ & 0.50 & 0.04 & 0.53 & 0.04 & & \\
\hline$c 772 /$ uas-dCreb2-b & 0.55 & 0.02 & 0.55 & 0.05 & & \\
\hline uas-shi/ $+29^{\circ} \mathrm{C}$ & 0.21 & 0.04 & 0.63 & 0.05 & & \\
\hline Feb170; uas-shi $29^{\circ} \mathrm{C}$ & -0.10 & 0.08 & -0.05 & 0.09 & & \\
\hline Wild-type + 3\% ethanol & & & & & 0.57 & 0.07 \\
\hline Wild-type + CXM, 3\% ethanol & & & & & 0.60 & 0.04 \\
\hline Wild-type - hs & & & & & 0.62 & 0.04 \\
\hline Wild-type + hs & & & & & 0.59 & 0.02 \\
\hline hs-dCreb2-b-hs & & & & & 0.72 & 0.06 \\
\hline$h s-d C r e b 2-b+h s$ & & & & & 0.64 & 0.03 \\
\hline uas-dCreb2-b/+ & & & & & 0.61 & 0.06 \\
\hline$c 772 /+$ & & & & & 0.63 & 0.06 \\
\hline$c 772 /$ uas-dCreb2-b & & & & & 0.70 & 0.02 \\
\hline MB247/+ & & & & & 0.73 & 0.05 \\
\hline MB247; uas-dCreb2-b & & & & & 0.69 & 0.04 \\
\hline$c 739 /+$ & & & & & 0.63 & 0.03 \\
\hline$c 739 /$ uas-dCreb2-b & & & & & 0.62 & 0.04 \\
\hline cer & & & & & 0.61 & 0.05 \\
\hline teq & & & & & 0.59 & 0.04 \\
\hline rsh & & & & & 0.64 & 0.06 \\
\hline uas-shi/+ & & & & & 0.60 & 0.02 \\
\hline c305a/+ & & & & & 0.60 & 0.04 \\
\hline c305a;uas-shi & & & & & 0.54 & 0.01 \\
\hline c739;uas-shi & & & & & 0.53 & 0.04 \\
\hline
\end{tabular}

There are no statistical differences between the relevant groups other than Feb170;uas-shits 1 flies, which display lower $\mathrm{OCT}$ and $\mathrm{MCH}$ acuity at $29^{\circ} \mathrm{C}$ (denoted in bold). Data are organized according to experiment and session of testing. All odor acuity, $n \geq 6$; sucrose acuity, $n \geq 4$. 0CT, 3-0ctanol; MCH, 4-methylcyclohexanol.

was tested at stated times after training. Except in Figure 7, flies were stored in empty vials containing only a water-dampened filter paper between training and testing. The performance index (PI) is calculated as the number of flies running toward the conditioned odor minus the number of flies running toward the unconditioned odor, divided by the total number of flies in the experiment. A single PI value is the average score from two groups of flies of the identical genotype trained with the reciprocal CS+/CS- odor combination (3-octanol or 4-methylcyclohexanol). To reduce variation between experiments, all genotypes were tested in parallel in each experimental session. We previously determined that the c316/+, c316-GAL4/uas-shi ${ }^{\text {ts1 }}$, Mz717/+, and Mz717GAL4/uas-shits1 flies have normal odor and sucrose acuity (Waddell et al., 2000; Keene et al., 2004, 2006) and c305a/+, c305a-GAL4; uas-shits1, c739/+, and c739-GAL4;uas-shits1 flies have normal odor acuity (Krashes et al., 2007). CXM feeding and manipulation of $r s h, \mathrm{cer}^{P}$, teq ${ }^{f 01792}$, and $h s-d C r e b 2-b$ (with and without heat shock) has previously been determined to have no adverse effect on odor acuity (Folkers et al., 1993; Yin et al., 1994; Comas et al., 2004; Didelot et al., 2006). We tested the sucrose acuity of the remaining stocks (Table 1) using a previously reported method (Keene et al., 2006).

We assayed fast phototaxis in a countercurrent apparatus (Benzer, 1967) using a simplified protocol of that described. Flies were knocked down into the start tube, the machine was laid flat on the table, and flies were given $30 \mathrm{~s}$ to run toward the light. Flies were then trapped and counted. The phototaxis index is the percentage of flies in the tube nearest the light. We similarly assayed negative geotaxis, except the countercurrent apparatus was positioned vertically. The geotaxis index is the percentage of flies in the top tube after $30 \mathrm{~s}$.

Statistical analyses were performed using KaleidaGraph (Synergy Software, Reading, PA). Overall, ANOVAs were followed by planned pairwise comparisons between the relevant groups with a Tukey's honestly 


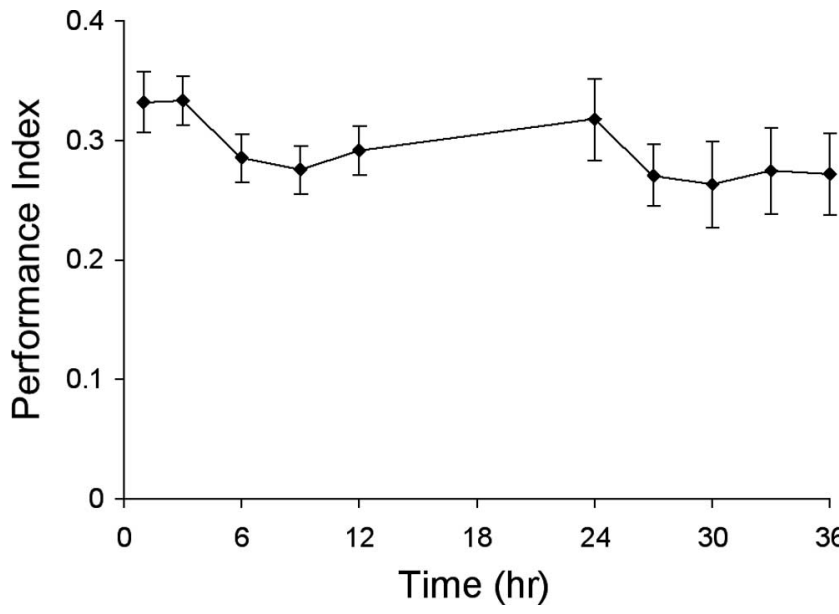

Figure 1. Persistent memory after a single session of appetitive conditioning. Wild-type flies were food deprived for $16-20 \mathrm{~h}$ and were conditioned with odor and sucrose reinforcement (as described in Materials and Methods). After training, they were housed in empty vials with water-dampened filter paper until they were tested. Different populations were tested once for odor memory 1, 3, 6, 9, 12, 24, 27, 30, 33, and $36 \mathrm{~h}$ after training. Beyond $36 \mathrm{~h}$, a significant number of animals perished, presumably of starvation. However, those that survived displayed robust memory performance. Error bars are SEM. All $n \geq 8$.

significant difference post hoc test. Unless stated otherwise, all olfactory conditioning experiments are $n \geq 8$.

\section{Results}

\section{Persistent memory after a single session of} appetitive conditioning

Formation of aversive olfactory LTM in Drosophila requires 5-10 sessions of associative conditioning with $15 \mathrm{~min}$ rest intervals between training bouts (spaced training) (Tully et al., 1994). The requirement for spaced training has been suggested to reflect the presence of a mechanistic threshold for LTM induction (Yin et al., 1994; Isabel et al., 2004) because a single training session, or even 10 training sessions, with no rest (massed training) does not form LTM (Tully et al., 1994).

Two reports of appetitive conditioning in Drosophila using a two-trial massed procedure observed measurable levels of memory up to $24 \mathrm{~h}$ after training (Tempel et al., 1983; Schwaerzel et al., 2007), and we previously determined that flies trained with a 2 min odor exposure paired with sucrose revealed robust memory performance up to $6 \mathrm{~h}$ (Keene et al., 2006; Krashes et al., 2007). We therefore further investigated the perdurance of appetitive memory following our previously described single conditioning session protocol.

Briefly, flies starved for $16-20 \mathrm{~h}$ were exposed to one odor without sugar reinforcement for $2 \mathrm{~min}$, followed by another odor with sugar reinforcement for $2 \mathrm{~min}$. Flies were then transferred to empty food vials (with a damp filter paper) and stored until testing. To test memory, flies were transported to a choice point in a T-maze where they were given 2 min to choose between the two odors experienced during training. We tested appetitive olfactory memory $1,3,6,9,12,24,27,30,33$, and $36 \mathrm{~h}$ after training. To our surprise, we found no significant decline in memory performance across this time period (Fig. 1). We reasoned that this robust $24 \mathrm{~h}$ memory after a single session of appetitive conditioning might be LTM. To test this, and to make as true a comparison as possible to previously described aversive LTM, we used a collection of the tools and protocols that were used in the defining studies (Tully et al., 1994; Yin et al., 1994).

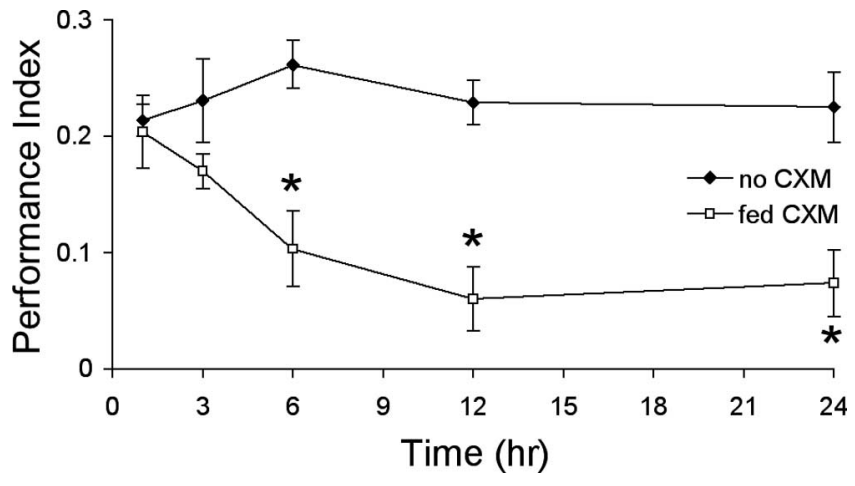

Figure 2. A single appetitive training session forms memory that requires new protein synthesis. Flies were either fed $35 \mathrm{~mm}$ CXM in 3\% ethanol solution (open squares) or 3\% ethanol alone (filled diamonds) during a $16 \mathrm{~h}$ starvation period before training. All flies were then trained, and different populations were tested once for odor memory 1, 3, 6, 12, or $24 \mathrm{~h}$ later. Error bars are SEM. Asterisks denote a significant difference $(p<0.05)$ at that time point from the performance of the other group. All $n \geq 8$.

\section{A single appetitive training session forms memory that requires new protein synthesis}

A hallmark of LTM in all organisms is a requirement for new protein synthesis after training (McGaugh, 1966; Daniels, 1971; Jaffe, 1980; Davis and Squire, 1984; Mizumori et al., 1985; Montarolo et al., 1986; Rose and Jork, 1987; Castellucci et al., 1989; Tully et al., 1994; Schafe and LeDoux, 2000). The classic method to assess a role for new protein synthesis in memory is to feed animals the protein synthesis inhibitor CXM before or after training. A CXM feeding regimen was established in Drosophila that results in an $\sim 50 \%$ decrease in overall protein synthesis (Tully et al., 1994), and this protocol has subsequently been used by several groups (Ge et al., 2004; Mery and Kawecki, 2005; Yu et al., 2006). However, our appetitive conditioning protocol requires that the flies are food deprived before training, and therefore we could not administer CXM in a glucose solution without compromising acquisition (data not shown). We therefore administered $35 \mathrm{~mm}$ CXM in a 3\% ethanol solution to the flies during the period of food deprivation before training. Following this protocol, we trained CXM-fed flies (and flies only fed 3\% ethanol) and tested them for memory at several time points after training. We observed a striking time-dependent decline in memory performance after CXM feeding, consistent with the notion that long-lasting appetitive odor memory requires new protein synthesis (Fig. 2).

CXM feeding did not significantly affect memory before $6 \mathrm{~h}$ after training, similar to memory formed after aversive conditioning (Tully et al., 1994). Three-hour memory performance, often referred to as middle-term memory (MTM), of CXM-fed flies was comparable to that of flies food deprived on vehicle alone $(p>0.1)$. However, memory tested 6,12 , or $24 \mathrm{~h}$ after training revealed a significant difference between the CXM and vehicle groups (all $p<0.002$ ), suggesting that a protein synthesisdependent memory phase partly guides behavior at that time.

Previous work demonstrated that $1 \mathrm{~d}$ memory after massed training was unaffected by CXM administration (Tully et al., 1994), suggesting the CXM-treated flies are healthy $24 \mathrm{~h}$ after training and that they have adequate acuity and agility to perform in the memory assay. However, because drug administration is a relatively crude approach, it was important that we similarly demonstrate a specific effect on appetitive LTM. Furthermore, whereas flies were stored on food before and after electric-shock training (Tully et al., 1994), the flies in our appetitive assay are 
subjected to long periods of starvation before and after training. It was therefore conceivable that the observed decline in performance after CXM treatment was simply a result of a timedependent decrease in health that was exacerbated by starvation. We therefore performed a control experiment to rule out this potential explanation.

We food deprived flies for 16-20 $\mathrm{h}$ in the presence of CXM or vehicle alone, and instead of training the flies, we transferred them to vials with a sucrose-impregnated filter paper for $2 \mathrm{~min}$. We reasoned this would emulate the sucrose exposure they normally receive in the training session. Flies were then transferred to vials containing a damp filter paper and stored for $24 \mathrm{~h}$. At that time, flies were conditioned and tested for $1 \mathrm{~h}$ memory. Onehour memory performance of CXM-fed flies $(0.33 \pm 0.03)$ was comparable $(n=8 ; p>0.6)$ to those fed vehicle alone $(0.31 \pm$ $0.03)$. Therefore, the combination of CXM administration and prolonged food deprivation does not generally compromise learning and memory performance $25 \mathrm{~h}$ after CXM feeding. Furthermore, CXM feeding did not affect sucrose acuity (Table 1) or odor acuity.

Therefore, these data demonstrate that one appetitive olfactory conditioning session forms bona fide LTM that is dependent on new protein synthesis, implying a clear difference in the requirements to induce appetitive and aversive olfactory LTM in Drosophila.

\section{Appetitive LTM depends on the action of cAMP response element-binding protein in the MBs}

The transcription factor cAMP response element-binding protein (CREB) is universally required for LTM, and it is widely believed that the requirement for new protein synthesis after training is, at least in part, a reflection of a need to translate transcripts from CREB-induced genes (Yin et al., 1994; Lonze and Ginty, 2002; Barco et al., 2003). A dominant-negative $d C r e b 2-b$ repressor transgene driven by the heat-shock promoter (hs-dCreb2-b) has been reported to produce a heat-shockdependent decrement of LTM formation (Yin et al., 1994; Perazzona et al., 2004). Inducing $d$ Creb2- $b$ with a 30 min heat shock $3 \mathrm{~h}$ before training specifically disrupted aversive LTM (Yin et al., 1994; Perazzona et al., 2004). We therefore tested whether induction of the $d C r e b 2-b$ transgene also impaired appetitive LTM after a single training session.

We induced the $d C r e b 2-b$ transgene by heat shocking fooddeprived flies at $37^{\circ} \mathrm{C}$ for $30 \mathrm{~min}$. We then allowed the flies to recover and express the transgene for $2 \mathrm{~h}$ before training. We subsequently trained the flies and measured their memory $24 \mathrm{~h}$ later. Induction of the $d C r e b 2-b$ transgene severely disrupted $24 \mathrm{~h}$ appetitive memory. Performance of $h s-d C r e b 2-b$ flies with heat shock was statistically different from $h s$ - $d C r e b 2-b$ flies without heat shock, wild-type flies with heat shock, and wild-type flies without heat shock (Fig. 3A) (all $p<0.006$ ). Furthermore, the performance of $h s$ - $d C r e b 2-b$ flies without heat shock was not statistically different from that of wild-type flies with and without heat shock ( $p>0.9$ and $p>0.4$, respectively), suggesting that any residual $d C r e b 2-b$ expression from the uninduced transgene did not disrupt appetitive LTM.

$d C r e b 2-b$ induction specifically disrupted LTM after multiple spaced trials of aversive conditioning and leaves both MTM and anesthesia-resistant memory (ARM) unaffected (Yin et al., 1994). We therefore tested whether $d C r e b 2-b$ expression specifically affected appetitive LTM by assaying appetitive MTM $3 \mathrm{~h}$ after training. Three-hour appetitive memory performance of flies with induced $d C r e b 2-b$ expression was comparable to all other
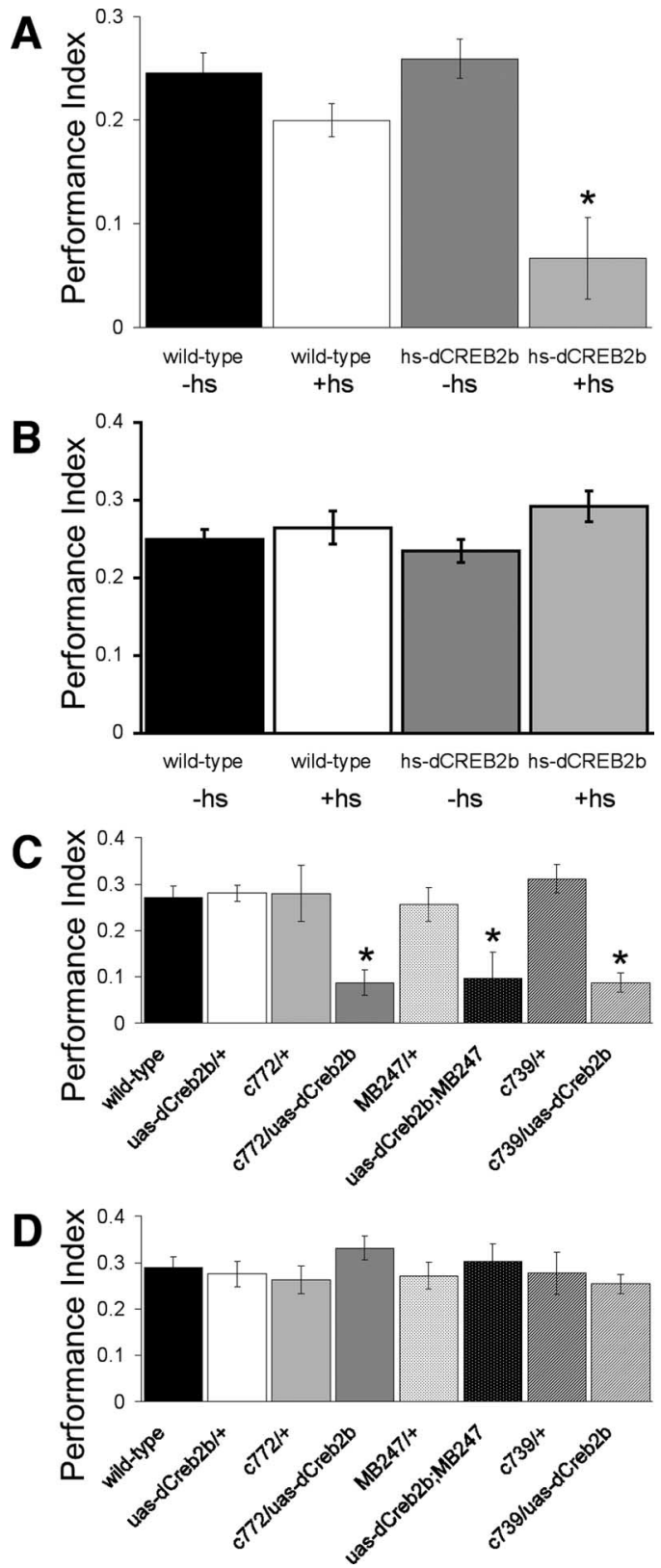

Figure 3. Inducible or region-restricted expression of dCREB2b disrupts appetitive LTM but not MTM. Wild-type flies and flies harboring an hs-dCreb2-b transgene were either heat shocked (+hs) for $30 \mathrm{~min} 2 \mathrm{~h}$ before training or were untreated ( $-\mathrm{hs}$ ). $\boldsymbol{A}, \boldsymbol{B}$, All groups were then trained and tested for $24 \mathrm{~h}$ memory $(\boldsymbol{A})$ or $3 \mathrm{~h}$ memory $(\boldsymbol{B})$. Flies harboring hs-dCreb2-b that were heat shocked displayed defective LTM compared with all other groups, but MTM was unaffected. $C$, Expressing a uas-dCreb2-b transgene in the MBs with $c 772$, MB247, and c739 GAL4 drivers disrupts LTM. Appetitive LTM performance of c772/uas-dCreb2-b, uas-dCreb2-b; MB247, and c739/uas-dCreb2-b flies was statistically different from all other groups. D, Appetitive MTM was not affected by expressing a uas-dCreb2-b transgene in the MBs. Error bars are SEM. Asterisks denote a significant difference $(p<0.05)$ from all other unmarked groups.

groups tested: $h s-d C r e b 2-b$ flies without heat shock and wild-type flies with and without heat shock (Fig. $3 B$ ) (all $p>0.06$ ). These data therefore demonstrate that formation of appetitive LTM after a single appetitive training session requires the acute action of CREB-dependent transcription.

Although controlling $d C r e b 2-b$ expression with the heatshock promoter allows fine temporal control, it does not provide any tissue specificity. Therefore, to compensate for this limitation, we also used the GAL4/UAS system to restrict expression of 
the $d C r e b 2-b$ repressor to the MBs. We combined a uas- $d C r e b 2-b$ transgene (Yu et al., 2006) with three different MB drivers: c739GAL4 (McGuire et al., 2001), c772-GAL4, and MB247-GAL4 (Zars et al., 2000). These drivers all express GAL4 strongly in the $\mathrm{MB} \alpha \beta$ neurons, whereas in addition, MB247 expresses GAL4 in the $\gamma$ neurons and $c 772$ also expresses in $\gamma$ and a few $\alpha^{\prime} \beta^{\prime}$ neurons (Krashes et al., 2007). Similar to our results with the $h s-d C r e b 2-b$ repressor, flies expressing uas-dCreb2-b in the MBs exhibited significantly reduced appetitive LTM measured $24 \mathrm{~h}$ after a single training session. Memory of c739/uas-dCreb2- $b$, c772/uas$d C r e b 2-b$, and uas- $d C r e b 2-b$;MB247 flies was statistically different from wild-type flies and flies that are heterozygous for the single transgenes alone: uas- $d C r e b 2-b /+, c 739 /+, c 772 /+$, and MB247/+ (Fig. 3C) $($ all $p<0.03)$.

The GAL4 approach expresses the uas- $d C r e b 2-b$ repressor throughout the development of the flies. We therefore verified that this manipulation did not affect earlier phases of appetitive memory after a single training session. MTM measured $3 \mathrm{~h}$ after training revealed no statistical differences between all groups of flies tested: wild-type, uas- $d C r e b 2-b /+, c 739 /$ uas- $d C r e b 2-b$, c772/uas- $d C r e b 2-b$, uas- $d C r e b 2-b$;MB247, c739/+, c772/+, and MB247/+ flies (Fig. 3D) (all $p>0.3$ ). Furthermore, all groups tested exhibited comparable odor and sucrose acuity to that of wild-type flies (Table 1).

Therefore, these data combining two approaches with either temporal or spatial control suggest that appetitive LTM, but not MTM, formed by a single training session requires the function of dCreb in the MBs. These data are consistent with findings for aversive LTM after spaced training (Yin et al., 1994; Perazzona et al., 2004; Yu et al., 2006).

\section{Appetitive LTM is rapidly consolidated within $2 \mathrm{~h}$ after training and requires radish}

The period of active memory consolidation in insects can be revealed by its sensitivity to cold-shock anesthesia (Erber, 1976; Quinn and Dudai, 1976; Tully et al., 1994). We therefore constructed a profile of memory consolidation after appetitive conditioning by assaying the effect on $24 \mathrm{~h}$ LTM of cold-shock anesthesia administered at different times before and after training. Flies were anesthetized by transferring them to prechilled vials and plunging them into a $4^{\circ} \mathrm{C}$ ice bath for $2 \mathrm{~min}$. This induces a rapid anesthesia that is reversed a few minutes after returning flies to $25^{\circ} \mathrm{C}$. LTM was severely reduced if cold shock was administered immediately after training but was unaffected if flies were anesthetized $1 \mathrm{~h}$ before training or 2 or $12 \mathrm{~h}$ after training. LTM performance of flies anesthetized immediately after training was significantly different from that of untreated flies $(p<0.006)$ and those anesthetized $1 \mathrm{~h}$ before training $(p<0.05)$, as well as those anesthetized 2 or $12 \mathrm{~h}$ after training $(p<0.03$ and $p<$ 0.001, respectively) (Fig. 4A). Furthermore, LTM performance of flies anesthetized $1 \mathrm{~h}$ before training, or 2 or $12 \mathrm{~h}$ after training, was comparable to LTM of untreated flies (all $p>0.8$ ). These data suggest that appetitive memory formed by our single $2 \mathrm{~min}$ training protocol is consolidated to the anesthesia-resistant form(s) within $2 \mathrm{~h}$ after training.

The published literature for aversive olfactory memory in Drosophila supports the existence of two forms of consolidated memory. Single and massed trials of aversive conditioning form ARM (Tully et al., 1994) that depends on the function of a wildtype radish gene (Folkers et al., 1993; Folkers et al., 2006). In contrast, spaced training forms both ARM and protein synthesisdependent LTM (Tully et al., 1994), although it is debated whether LTM and ARM exist in parallel or are mutually exclusive
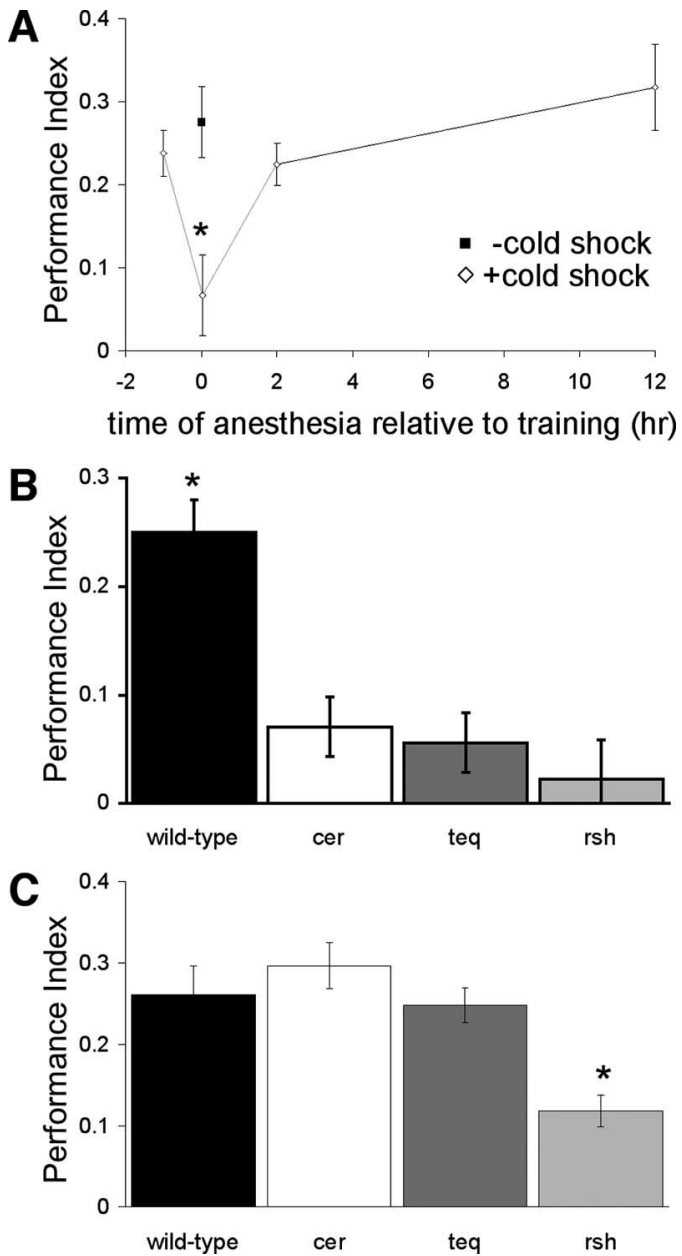

Figure 4. Appetitive memory is quickly consolidated and is disrupted by crammer, tequila, and radish mutation. $\boldsymbol{A}$, Appetitive memory becomes resistant to disruption by cold-shock anesthesia within $2 \mathrm{~h}$ after training. Different populations of wild-type flies were subjected to a 2 min cold-shock anesthesia $1 \mathrm{~h}$ before, immediately after, or 2 or $12 \mathrm{~h}$ after training (open diamonds). They were then allowed to recover and were tested for $24 \mathrm{~h}$ appetitive memory. Only the performance of flies that were anesthetized immediately after training differed from that of the other groups and from flies that had not been anesthetized (filled square). All $n \geq 8$. $\boldsymbol{B}$, Twenty-four-hour appetitive memory is disrupted in crammer, tequila, and radish mutant flies. Twenty-four-hour memory performance of cer, teq, and $r$ sh mutant flies was statistically different from wild-type flies. All $n \geq 12$. C, Three-hour appetitive MTM is unaffected by cer and teq mutation but is significantly disrupted by rsh mutation. Three-hour memory performance of $r$ sh flies was statistically different from that of all other groups. All $n \geq 11$. Error bars are SEM. Asterisks denote a significant difference $(p<0.05)$ from all other unmarked groups.

(Tully et al., 1994; Isabel et al., 2004). Because formation of appetitive LTM does not require spaced interval training, we investigated the involvement of $r s$ in appetitive LTM after a single training session.

We trained wild-type and $r s h$ mutant flies (Folkers et al., 1993) and tested them for $24 \mathrm{~h} \mathrm{LTM}$. Surprisingly, appetitive LTM was abolished in $r s h$ mutant flies, suggesting that both ARM and protein synthesis-dependent components depend on rsh function (Fig. $4 B$ ). Performance of $r s h$ mutant flies was statistically different from wild-type flies $(p<0.0001)$. We also tested $3 \mathrm{~h}$ appetitive MTM performance of $r s h$ mutant flies. MTM performance of $r s$ flies was statistically different from and approximately half that of wild-type flies $(p<0.01)$ (Fig. $4 C)$, similar to that observed with aversive MTM (Folkers et al., 1993, 2006). These data are consistent with a published report that $3 \mathrm{~h}$ appetitive MTM is 
disrupted after a 1 min cold-shock anesthesia administered 30 min before testing (Schwaerzel et al., 2007).

Taken with previously published work, these data suggest that a single appetitive training session forms both anesthesiasensitive memory, rsh-dependent consolidated memory, and protein synthesis-dependent LTM. Furthermore, the finding that LTM is absent in rsh mutants suggests that rsh is required for appetitive LTM, questioning the proposed mechanistic independence of ARM and LTM (Tully et al., 1994; Isabel et al., 2004).

\section{The crammer and tequila LTM-specific mutants disrupt appetitive LTM}

Our unexpected finding that the $r$ sh mutation abolished appetitive LTM after a single training session led us to question the role of the crammer (cer) and tequila (teq) genes that have both been reported to specifically disrupt protein synthesis-dependent aversive LTM (Comas et al., 2004; Didelot et al., 2006). The cer gene encodes an inhibitor of the cathepsin subfamily of cysteine protease and is expressed in MB neurons and surrounding glial cells (Comas et al., 2004), whereas teq encodes a Drosophila ortholog of neurotrypsin serine protease [although this has been debated (Sonderegger and Patthy, 2007)] and its expression increases transiently after spaced training (Didelot et al., 2006).

We tested appetitive LTM performance of mutant flies carrying hypomorphic transposable element insertions in the $\operatorname{cer}\left(\mathrm{cer}^{P}\right)$ and teq (teq ${ }^{f 01792}$ ) genes (Comas et al., 2004; Didelot et al., 2006). Appetitive LTM measured $24 \mathrm{~h}$ after training was severely disrupted in both $\operatorname{cer}^{P}$ and $t e q^{f 01792}$ flies. Performance of $\operatorname{cer}^{P}$ and teq ${ }^{f 01792}$ mutant flies was statistically different from wild-type flies (both $p<0.0002$ ) (Fig. $4 B$ ). To verify that the mutant defect was specific to LTM, we also assayed the $\operatorname{cer}^{P}$ and teq ${ }^{\text {fol }}{ }^{2}$ mutant flies for MTM $3 \mathrm{~h}$ after training. MTM performance of $\operatorname{cer}^{P}$ and teq $q^{f 01792}$ mutant flies was comparable to that of wild-type flies (both $p>0.8$ ) (Fig. 4C), suggesting that a single training session induces MTM but not LTM in $\operatorname{cer}^{P}$ and teq ${ }^{\text {fol792 }}$ mutant flies.

Therefore, the LTM-specific $\operatorname{cer}^{P}$ and teq $q^{f 01792}$ mutant flies provide independent evidence that a single appetitive training session forms protein synthesis-dependent LTM with some mechanistic similarity to aversive LTM that can only be formed by multiple spaced training trials.

\section{DPM neurons and MB $\boldsymbol{\alpha}^{\prime} \boldsymbol{\beta}^{\prime}$ neurons are critical for formation of appetitive LTM}

We previously demonstrated that neurotransmission from both DPM neurons and MB $\alpha^{\prime} \beta^{\prime}$ neurons is critical during the first 30-60 min after training for stable $3 \mathrm{~h}$ appetitive MTM (Keene et al., 2006; Krashes et al., 2007), whereas output from $\mathrm{MB} \alpha \beta$ neurons is required for appetitive MTM retrieval (Schwaerzel et al., 2003; Krashes et al., 2007). Because our experiments demonstrate that cold-shock anesthesia within the first few minutes after training severely disrupts appetitive memory (Fig. $4 A$ ), we tested for a role of DPM neurons and $\mathrm{MB} \alpha^{\prime} \beta^{\prime}$ neurons during this time window in appetitive LTM. For these experiments, we used neuron-specific expression of the dominant temperaturesensitive shibire ${ }^{\mathrm{ts} 1}\left(s h i^{\mathrm{ts} 1}\right)$ transgene (Kitamoto, 2001). shi $i^{\text {ts1 }}$ blocks dynamin-dependent membrane recycling and thereby synaptic vesicle release at the restrictive temperature of $31^{\circ} \mathrm{C}$, and this blockade is reversible by returning flies to the permissive temperature of $25^{\circ} \mathrm{C}$.

We used the c316-GAL4 and Mz717-GAL4 lines to test the role of DPM neurons (Waddell et al., 2000; Keene et al., 2004), the $\mathrm{c} 305 \mathrm{a}-\mathrm{GAL} 4$ line to test the role of $\mathrm{MB} \alpha^{\prime} \beta^{\prime}$ neurons (Krashes et al., 2007), and the c739-GAL4 line to test for the role of MB $\alpha \beta$ neurons (McGuire et al., 2001; Krashes et al., 2007) in appetitive LTM. At $25^{\circ} \mathrm{C}$, appetitive LTM performance of wild-type, uasshit ${ }^{\text {ts1 }}, \mathrm{c} 316 /+$, c316/uas- $s h i^{\text {ts1 }}$, Mz717/+, Mz717/uas- shit ${ }^{\text {ts1 }}$, c305a/+, c305a; uas-shi ${ }^{\text {ts } 1}, \mathrm{c} 739 /+$, and c739;uas-shi ${ }^{\text {ts } 1}$ flies was comparable across groups (all $p>0.9$ ) (Fig. $5 A$ ). We therefore tested whether DPM, MB $\alpha^{\prime} \beta^{\prime}$, and $\mathrm{MB} \alpha \beta$ neuron output was required during the first hour after training (Fig. $5 B$ ). Flies were trained at the permissive temperature and shifted immediately after training to the restrictive temperature for $60 \mathrm{~min}$, blocking $\mathrm{DPM}, \mathrm{MB} \alpha^{\prime} \beta^{\prime}$, and $\mathrm{MB} \alpha \beta$ neurotransmission. The flies were then stored at the permissive temperature and tested for memory performance $23 \mathrm{~h}$ later. DPM and $\mathrm{MB} \alpha^{\prime} \beta^{\prime}$ neuron manipulation severely impaired LTM, but blocking MB $\alpha \beta$ neurons did not (Fig. 5B). Memory of c316/uas-shits ${ }^{\text {ts1 }}$ Mz717/uas-shits ${ }^{\text {ts }}$ and c305a; uas-shit ${ }^{\text {ts }}$ flies was statistically different from wild-type, uas- $s h i^{\text {tsl }}$, and c739; uas-shit ${ }^{\text {ts }}$ flies (all $p<0.03$ ), whereas memory of c739; uas-shits ${ }^{\text {tsl }}$ flies was comparable to that of wild-type and uas-shitsl flies (both $p>0.9$ ). These data suggest that output from both DPM and MB $\alpha^{\prime} \beta^{\prime}$ neurons is required during the first hour after training for appetitive LTM, whereas $\mathrm{MB} \alpha \beta$ neuron output is dispensable.

MB $\alpha \beta$ neuron output is required for retrieval of aversive odor memory after a single training trial (Dubnau et al., 2001; McGuire et al., 2001; Krashes et al., 2007), for appetitive odor memory after two trials (Schwaerzel et al., 2003), and for aversive memory after spaced training (Isabel et al., 2004). We therefore tested the role of DPM, MB $\alpha^{\prime} \beta^{\prime}$, and MB $\alpha \beta$ neuron output during appetitive LTM retrieval. We trained flies at the permissive temperature and stored them at the permissive temperature for $24 \mathrm{~h}$. At this time point, we blocked DPM, MB $\alpha^{\prime} \beta^{\prime}$ neuron, or $\mathrm{MB} \alpha \beta$ neuron output by shifting the flies to the restrictive temperature and tested them for $24 \mathrm{~h}$ LTM. Strikingly, this manipulation severely impaired memory if $\alpha \beta$ neuron output was blocked but did not affect performance if DPM or MB $\alpha^{\prime} \beta^{\prime}$ neurons were blocked (Fig. 5C). Memory of c739; uas-shi ${ }^{{ }^{\text {ts } 1}}$ flies was statistically different from wild-type, uas-shits ${ }^{\text {ts }}, \mathrm{c} 316 / \mathrm{uas}^{-s h} i^{\mathrm{ts} 1}$, Mz717/uas-shits ${ }^{\text {ts1 }}$ and c305a;uas-shit flies (all $p<0.01$ ), whereas the performance of c316/uas-shits ${ }^{\text {ts1 }}$ Mz717/uas-shits ${ }^{\text {ts }}$, and c305a;uas-shits ${ }^{\text {ts1 }}$ flies was comparable to that of wild-type and uas-shi ${ }^{\text {tsl }}$ flies (all $p>0.08$ ).

Therefore, the fly processes appetitive LTM using the same parallel and sequential neural circuit mechanism that it uses to process MTM (Krashes et al., 2007). MB $\alpha^{\prime} \beta^{\prime}$ neurons and DPM neurons are transiently required within the first hour after training to consolidate appetitive LTM, and output from $\alpha \beta$ neurons is exclusively required to retrieve LTM. These data, taken with our previous work, indicate that appetitive LTM is mechanistically linked to appetitive MTM (Keene et al., 2006; Krashes et al., 2007).

\section{Evidence against a role for EB ring neurons in LTM retrieval} A plausible caveat of the 739 driver line is that, in addition to strongly expressing in $\mathrm{MB} \alpha \beta$ neurons, it expresses in a specific subset of EB ring neurons in the central complex (Hanesch et al., 1989; Renn et al., 1999; Wu et al., 2007). Wu et al. (2007) proposed that aversive LTM consolidation involved "transfer" from $\mathrm{MB}$ to the ring neurons in the EB. Using the Feb170 driver line, they concluded that transmission from EB neurons was required to retrieve aversive LTM. We therefore tested for a role of Feb170 EB neurons in appetitive LTM retrieval. We assayed RuslanGAL4 (Dubnau et al., 2003; Wu et al., 2007) and c547 (Renn et al., 1999) that also express in EB neurons, in parallel for comparison 

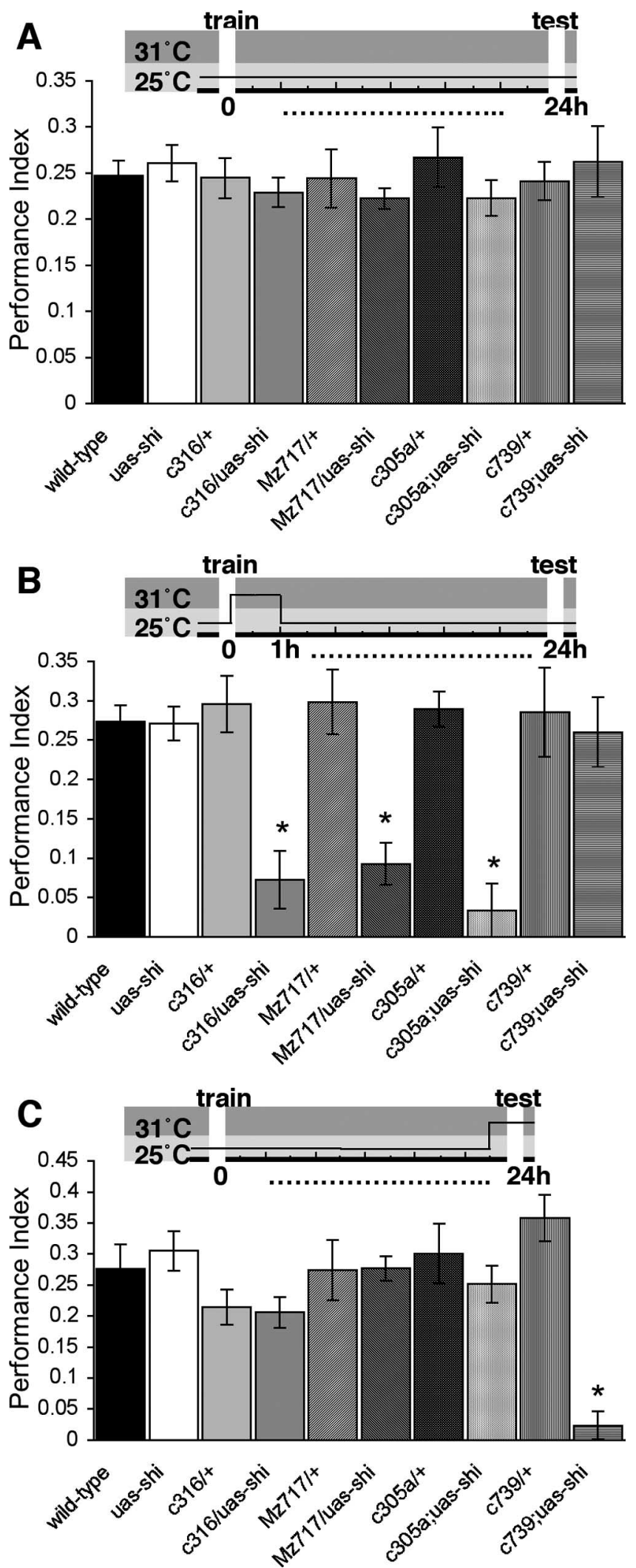

Figure 5. Neurotransmission from $M B \alpha^{\prime} \beta^{\prime}$ neurons and DPM neurons is required for consolidation of appetitive LTM, whereas transmission from $\mathrm{MB} \alpha \beta$ neurons is only required for retrieval. The temperature shift protocols are shown pictographically above each graph. $A$, The permissive temperature of $25^{\circ} \mathrm{C}$ does not affect $24 \mathrm{~h}$ appetitive LTM of any of the lines used in this study. All genotypes were trained and tested for $24 \mathrm{~h}$ memory at $25^{\circ} \mathrm{C}$. All $n \geq 8$. B, Blocking DPM neuron or $\mathrm{MB} \alpha^{\prime} \beta^{\prime}$ neuron output, but not $\mathrm{MB} \alpha \beta$ neuron output, for $1 \mathrm{~h}$ immediately after training severely impairs $24 \mathrm{~h}$ appetitive LTM. Flies were trained at $25^{\circ} \mathrm{C}$, and immediately after training, they were shifted to $31^{\circ} \mathrm{C}$ for $60 \mathrm{~min}$. Flies were then returned to $25^{\circ} \mathrm{C}$ and stored
(Fig. 6). We first noticed that the majority of Feb170;uas-shits1 flies died during starvation. Furthermore, on shifting to the restrictive temperature, surviving Feb170; uas-shits ${ }^{\text {ts }}$ and c547; uas-shit ${ }^{\text {ts } 1}$ flies exhibited reduced mobility, consistent with a previous study describing a role for the central complex in locomotion (Strauss and Heisenberg, 1993). Therefore, although appetitive LTM performance of Feb170; uas-shi ${ }^{\text {tsl }}$ flies and c547; uas-shis $i^{\text {ts }}$ flies was significantly impaired, this is confounded by poor locomotor activity. Indeed, additional testing revealed that fed Feb170; uas-shits ${ }^{\text {ts }}$ and $\mathrm{c} 547$; uas-shis ${ }^{\text {ts1 }}$ flies failed olfactory acuity (Table 1), fast phototaxis (Fig. 6E) and geotaxis (Fig. 6F) tests that require locomotor competence at the restrictive temperature $\left(29-31^{\circ} \mathrm{C}\right)$. In contrast, Ruslan;uas-shits ${ }^{\text {tsl }}$ flies had normal locomotor behavior and appetitive LTM retrieval. Although these lines may inactivate different subsets of EB neurons (Hanesch et al., 1989; Renn et al., 1999), these data challenge the utility of the Feb170 line for memory analysis and question the proposed role for the EB in LTM retrieval.

\section{Extension of the LTM assay: satiety state regulates memory retrieval}

It is necessary to food deprive flies before and after appetitive learning for them to display appetitive memory. This critical hunger drive is of great interest, but it imposes an obvious limitation on the appetitive LTM assay because starving flies for more than $2 \mathrm{~d}$ compromises viability. In our experiments described here, the flies that were tested for $36 \mathrm{~h}$ memory (Fig. 1) were starved for $16-20 \mathrm{~h}$ before training and up to $36 \mathrm{~h}$ after training. Beyond $36 \mathrm{~h}$, a significant number of flies died, presumably of starvation. We therefore investigated whether we could extend the utility of the assay by feeding and restarving flies after training (Fig. 7). We food deprived two groups of flies for 16-20 h, trained them both using the standard protocol, and put them both into food vials for $24 \mathrm{~h}$. One group was allowed to feed for an additional $24 \mathrm{~h}$ (group A), whereas the other was food deprived for $24 \mathrm{~h}$ (group B). We subsequently assayed the flies in groups A and $\mathrm{B}$ in parallel for $48 \mathrm{~h}$ appetitive memory. Strikingly, flies in group A that had been fed ad libitum between training and testing displayed little memory performance $(0.08 \pm 0.03)$, whereas those that had been restarved in group B exhibited robust memory performance $(0.25 \pm 0.03)$. The appetitive LTM performance of group A flies was significantly different from that of the group B $(p<0.005)$. These data therefore demonstrate that feeding to satiety suppresses memory retrieval and that this suppression can be reversed by subsequently restarving the flies before testing. Furthermore, this feeding and restarving protocol allows one to extend the time period that is available to study the mechanisms of appetitive memory.

\section{Discussion}

One conditioning session forms appetitive LTM

A single 2 min training session pairing odor with sucrose forms appetitive memory that lasts for days. We cautiously use the term "session" rather than "trial" because, although the conditioned odor stimulus is continuously presented for $2 \mathrm{~min}$, we do not

in empty vials until they were tested for $24 \mathrm{~h}$ appetitive LTM at $25^{\circ} \mathrm{C}$. All $n \geq 11$. C, Blocking MB $\alpha \beta$ neuron output, but not DPM neuron or $\mathrm{MB} \alpha^{\prime} \beta^{\prime}$ neuron output, during testing abolishes $24 \mathrm{~h}$ appetitive $L T M$. Flies were trained at $25^{\circ} \mathrm{C}$ and stored in empty vials for $24 \mathrm{~h}$. They were then shifted to $31^{\circ} \mathrm{C}$ for $15 \mathrm{~min}$ before they were tested for appetitive LTM. All $n \geq 8$. Error bars are SEM. Asterisks denote a significant difference $(p<0.05$ ) from all other unmarked groups. All flies harbor one copy of the uas-shi ${ }^{\text {ts1 }}$ transgene. 

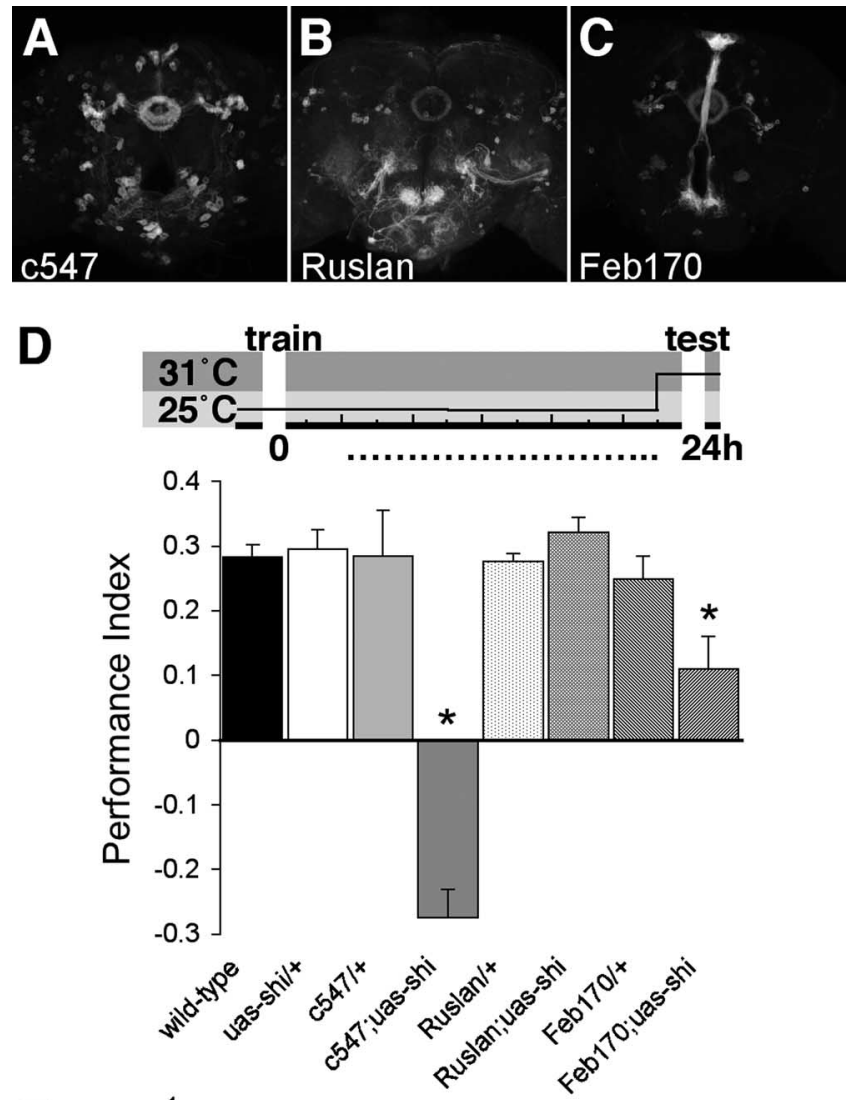

E
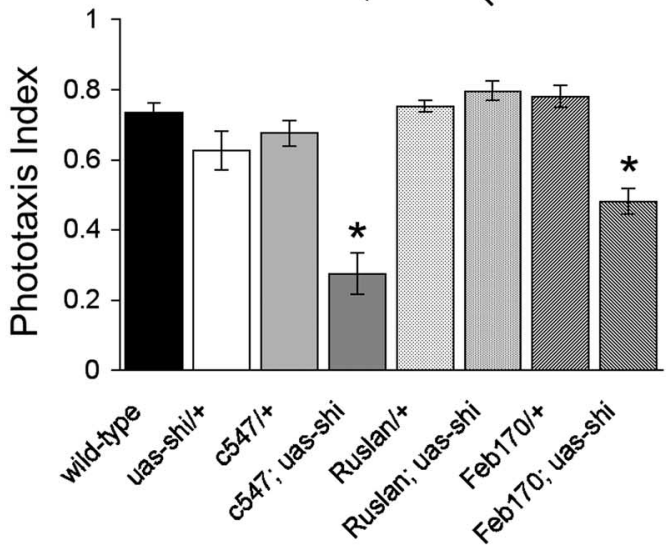

$\mathbf{F}$

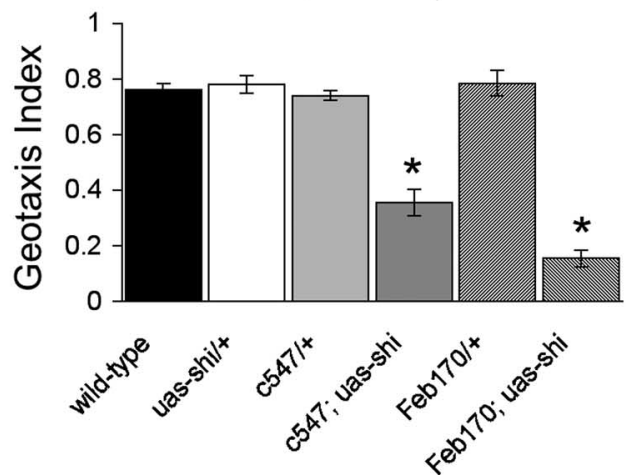

Figure 6. Evidence against a role for EB ring neurons in LTM retrieval. $A-C$, Projections of the entire midbrain of flies driving a uas-CD8::GFP transgene with the $c 547(\boldsymbol{A})$, Ruslan $(\boldsymbol{B})$, and Feb170 ( $($ ) enhancer trap lines. All lines show clear expression in R2/R4 ring neurons in the outer layers of the EB compared with $\mathrm{R} 1 / \mathrm{R} 3$ neurons in $\mathrm{C} 339$ (data not shown). The driver name is listed in the lower left-hand corner of each panel. D, Blocking c547 or Feb170 neurons, but not Ruslan neuron output, for $15 \mathrm{~min}$ before and during testing impairs $24 \mathrm{~h}$ appetitive LTM performance. The temperature shift protocol is shown pictographically. All genotypes were trained at $25^{\circ} \mathrm{C}$ and tested for $24 \mathrm{~h}$ memory at $31^{\circ} \mathrm{C}$. All flies with uas-shi ${ }^{\text {ts } 1}, n \geq 8$; heterozygous GAL $4 /+$

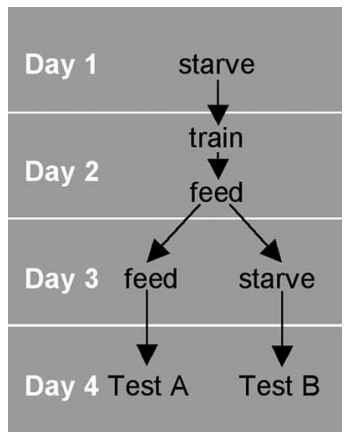

Figure 7. Experiment to test whether satiation reversibly suppresses memory retrieval. Wild-type flies were starved for $16-20 \mathrm{~h}$, trained with a single appetitive conditioning session, and were either returned to food vials for $48 \mathrm{~h}$ (group A) or for $24 \mathrm{~h}$ and then subsequently food deprived for the next $24 \mathrm{~h}$ (group B). Both groups were trained, stored, and tested for $48 \mathrm{~h}$ appetitive LTM at $25^{\circ} \mathrm{C}$.

know how often the flies sample the sugar unconditioned stimulus. One session of the established aversive training paradigm presents 12 shocks at $5 \mathrm{~s}$ intervals overlapping with 1-min-long odor exposure (Tully and Quinn, 1985), and therefore neither protocol is strictly "single-trial" learning. Nevertheless, our results present a profound difference between the training protocol requirements to form aversive and appetitive LTM in flies. Formation of aversive LTM requires 5-10 training sessions with rest intervals (Tully et al., 1994), whereas a single 2 min session is sufficient to form robust protein synthesis-dependent appetitive LTM. Appetitive LTM is disrupted by CXM feeding, inhibition of CREB-dependent transcription (Tully et al., 1994; Yin et al., 1994), and the crammer (Comas et al., 2004) and tequila (Didelot et al., 2006) genes, which suggests that it is bona fide LTM. Furthermore, these data indicate some mechanistic parallel between aversive and appetitive LTM.

Appetitive conditioning forms more distributed memory traces in the brain (Thum et al., 2007) and more efficiently forms LTM than aversive conditioning. We speculate that these properties of appetitive memory result from the ethological relevance of feeding and the salience of sucrose reinforcement. Furthermore, the salience is likely to be enhanced in hungry flies because they are motivated to seek food. There are a few other reports of single-trial training forming LTM. With the notable exception of fear conditioning in rodents (Fanselow, 1980), most involve feeding behavior and the gustatory pathway. In conditioned taste aversion experiments, rodents develop a long-lasting avoidance of a novel tastant after a single exposure of the tastant and delayed drug-induced malaise (Garcia et al., 1955). Similarly, pond snails develop long-lasting conditioned taste aversion if carrot juice is paired with salt exposure (Sugai et al., 2007), and 1-d-old chicks develop LTM to avoid pecking a colored bead if that bead was tainted with a bitter tasting compound when first presented (Lossner and Rose, 1983). There are also examples in which single-trial conditioning forms appetitive LTM. Rats deficient in thiamine can be trained to prefer non-nutritious saccharinflavored water by pairing it with delayed an intramuscular thiamine injection (Garcia et al., 1967). Pond snails form appetitive

$\leftarrow$

flies, $n \geq 4$. $E$, Blocking c547 or Feb170 neurons, but not Ruslan neurons, impairs phototaxis performance. All flies were tested at $31^{\circ} \mathrm{C}$. $\boldsymbol{F}$, Blocking $c 547$ neurons or Feb 170 neurons impairs negative geotaxis performance. All flies were tested at $31^{\circ}$. All $n \geq 6$. Error bars are SEM. Asterisks denote a significant difference $(p<0.05)$ from all other unmarked groups. All flies harbor one copy of the uas-shi ${ }^{\text {ts } 1}$ transgene. 
LTM for the odorant/tastant amylacetate after a single trial of appetitive conditioning pairing it with sucrose (Fulton et al., 2005). Last, a single trial of appetitive conditioning in honeybees forms robust day-long memory that, surprisingly, does not require new protein synthesis after training (Menzel, 2001). Therefore, it is possible that the innate importance of food-seeking behavior and memory makes it particularly prone to fast consolidation to LTM.

\section{Fast consolidation to LTM}

The single training session appetitive LTM assay provides a unique advantage for the study of memory consolidation because one can manipulate the brain immediately after training during the initial period of memory formation. In contrast, 10 cycles of aversive spaced training takes $150 \mathrm{~min}$ to complete (Tully et al., 1994), and therefore one cannot perturb neural processing during this period without also interfering with acquisition. Using cold-shock anesthesia, we found that appetitive memory is quickly, and perhaps entirely, consolidated to anesthesiaresistant forms within $2 \mathrm{~h}$ after training.

Previous work in flies suggests that cold shock-resistant memory can be broken into two independent components, ARM that depends on the rsh gene and is resistant to CXM and LTM that is unaffected by rsh and is sensitive to CXM (Tully et al., 1994; Isabel et al., 2004). Feeding flies CXM disrupted appetitive LTM and produced a statistically significant defect $6 \mathrm{~h}$ after training, suggesting that protein synthesis-dependent LTM guides behavior at that time. Although the effect of CXM feeding is estimated to inhibit only $50 \%$ of global protein synthesis (Tully et al., 1994) and has to be partial, these data are consistent with the notion that consolidated memory before $6 \mathrm{~h}$ might be ARM. However, whereas aversive LTM requires protein synthesis and is not affected by rsh (Tully et al., 1994), appetitive LTM requires new protein synthesis and $r s h$, suggesting appetitive LTM and $r s h$ dependent appetitive memory do not represent separable memory phases. This result highlights a potentially major mechanistic difference between aversive and appetitive LTM, and that the relationship between ARM and LTM is worth revisiting. Unfortunately, the recent cloning of $r$ sh does not provide any mechanistic insight because its primary sequence does not contain any known functional domains (Folkers et al., 2006).

Our data reveal a slight discrepancy in the notion that $r s h$, dCreb-dependent transcription and new protein synthesis are all necessary components of appetitive LTM. Cold-shock anesthesia indicates that appetitive memory consolidation is nearly complete $2 \mathrm{~h}$ after training and $r$ sh mutant flies display defective performance $3 \mathrm{~h}$ after training, but neither dCreb2-b nor CXM feeding produced a significant difference in memory performance $3 \mathrm{~h}$ after training. We speculate that expression of early forms of appetitive LTM (E-LTM) depend on $r s h$ and that because radish protein immunolocalized to neuropil (Folkers et al., 2006), radish might function in a synaptic tagging process that marks the relevant synapses for capture of dCreb2-dependent transcripts. This idea provides a plausible reason why radish is required both for E-LTM and for later appetitive LTM (L-LTM), whereas dCreb2-b only interferes with L-LTM. Similarly, we posit that CXM feeding blocks the translation of mRNAs that are direct and indirect targets of CREB and that are necessary for L-LTM. Similar models have been proposed based on work in rodents and Aplysia (Frey and Morris, 1997; Martin et al., 1997; Casadio et al., 1999; Barco et al., 2002; Si et al., 2003).

\section{A neural circuit perspective}

We previously determined that stable olfactory memory (MTM) observed $3 \mathrm{~h}$ after aversive and appetitive training requires the sequential involvement of different $\mathrm{MB}$ neuron subsets. $\mathrm{MB} \alpha^{\prime} \beta^{\prime}$ neurons are required during and after training to acquire and stabilize memory (Krashes et al., 2007), whereas MB $\alpha \beta$ neuron output is only required to retrieve the memory (Dubnau et al., 2001; McGuire et al., 2001; Schwaerzel et al., 2003; Krashes et al., 2007). Stable aversive and appetitive MTM also requires the action of MB-innervating DPM neurons during the first hour after training (Keene et al., 2004, 2006; Yu et al., 2005; Krashes et al., 2007). Similarly timed manipulation of these distinct neural circuit elements strongly impairs appetitive LTM, suggesting a tight mechanistic link between appetitive MTM and LTM.

Finding that consolidation of appetitive memory to a protein synthesis-dependent form requires the DPM-MB neural circuitry and that retrieval requires $\mathrm{MB} \alpha \beta$ neuron output is consistent with the idea that consolidated memory is represented in $\mathrm{MB} \alpha \beta$ neurons themselves. Several studies have now reported that $\mathrm{MB}$ neuron output is required to retrieve olfactory memory (Dubnau et al., 2001; McGuire et al., 2001; Schwaerzel et al., 2003; Krashes et al., 2007), and a few have indicated that MB $\alpha \beta$ neurons are particularly important to retrieve aversive and appetitive MTM (McGuire et al., 2001; Krashes et al., 2007) or aversive LTM (Isabel et al., 2004). A recent live-imaging study provided additional evidence that consolidated aversive LTM is represented in $\operatorname{MB} \alpha \beta$ neurons (Yu et al., 2006). Flies that had been space trained with odor and shock exhibited enhanced odor-evoked $\mathrm{Ca}^{2+}$ signals in the vertical $\alpha$ branch of MB $\alpha \beta$ neurons 9-24 h after conditioning. The development of this memory "trace" was disrupted by CXM administration, by mutations in the amnesiac gene, and by expressing a transgenic $d C r e b 2-b$ in $\mathrm{MB} \alpha \beta$ neurons. Furthermore, expression of the dCreb2-b transgene in $\mathrm{MB} \alpha \beta$ neurons also impaired aversive LTM behavior. These data are highly consistent with our findings described here for appetitive LTM after a single training session and therefore indicate that there are common mechanistic components to aversive and appetitive LTM. It is also worth noting that radish is strongly expressed in $\mathrm{MB} \alpha \beta$ neurons (Folkers et al., 2006). Therefore, this collection of findings provides strong evidence that consolidated aversive and appetitive LTM involves $\mathrm{MB} \alpha \beta$ neurons.

Our results do not support the recently proposed idea that LTM consolidation involves transfer from MB to EB (Wu et al., 2007). Although we used an appetitive memory assay, we found that Feb170; uas-shis ${ }^{\text {ts }}$ flies have a pronounced locomotor defect and therefore these flies are not suitable for memory analysis. Furthermore, Ruslan GAL4 (Wu et al., 2007) and c305a (Krashes et al., 2007) express in EB ring neurons, but blocking these neurons does not affect appetitive LTM retrieval. Our data are instead consistent with the notion that the transfer of the MB lobe requirement within the first few hours after training may be the fly equivalent of systems consolidation.

\section{Motivational control of appetitive memory retrieval}

Our data clearly demonstrate that flies have to be hungry to effectively retrieve appetitive memory. Feeding them ad libitum after training suppressed memory performance, but restarving them restored memory performance. We propose this apparent context dependence of appetitive memory retrieval reflects a motivational state to seek food and therefore predict it is regulated by neuromodulatory systems that signal hunger (Melcher et al., 2007). 


\section{References}

Barco A, Alarcon JM, Kandel ER (2002) Expression of constitutively active CREB protein facilitates the late phase of long-term potentiation by enhancing synaptic capture. Cell 108:689-703.

Barco A, Pittenger C, Kandel ER (2003) CREB, memory enhancement and the treatment of memory disorders: promises, pitfalls and prospects. Expert Opin Ther Targets 7:101-114.

Benzer S (1967) Behavioral mutants of Drosophila isolated by countercurrent distribution. Proc Natl Acad Sci USA 58:1112-1119.

Carew TJ, Pinsker HM, Kandel ER (1972) Long-term habituation of a defensive withdrawal reflex in Aplysia. Science 175:451-454.

Casadio A, Martin KC, Giustetto M, Zhu H, Chen M, Bartsch D, Bailey CH, Kandel ER (1999) A transient, neuron-wide form of CREB-mediated long-term facilitation can be stabilized at specific synapses by local protein synthesis. Cell 99:221-237.

Castellucci VF, Blumenfeld H, Goelet P, Kandel ER (1989) Inhibitor of protein synthesis blocks long-term behavioral sensitization in the isolated gill-withdrawal reflex of Aplysia. J Neurobiol 20:1-9.

Comas D, Petit F, Preat T (2004) Drosophila long-term memory formation involves regulation of cathepsin activity. Nature 430:460-463.

Dahanukar A, Lei YT, Kwon JY, Carlson JR (2007) Two gr genes underlie sugar reception in Drosophila. Neuron 56:503-516.

Daniels D (1971) Acquisition, storage, and recall of memory for brightness discrimination by rats following intracerebral infusion of acetoxycycloheximide. J Comp Physiol Psychol 76:110-118.

Davis HP, Squire LR (1984) Protein synthesis and memory: a review. Psychol Bull 96:518-559.

Didelot G, Molinari F, Tchenio P, Comas D, Milhiet E, Munnich A, Colleaux L, Preat T (2006) Tequila, a neurotrypsin ortholog, regulates long-term memory formation in Drosophila. Science 313:851-853.

Dubnau J, Grady L, Kitamoto T, Tully T (2001) Disruption of neurotransmission in Drosophila mushroom body blocks retrieval but not acquisition of memory. Nature 411:476-480.

Dubnau J, Chiang AS, Grady L, Barditch J, Gossweiler S, McNeil J, Smith P, Buldoc F, Scott R, Certa U, Broger C, Tully T (2003) The staufen/pumilio pathway is involved in Drosophila long-term memory. Curr Biol 13:286-296.

Ebbinghaus H (1885) Über das Gedächtnis (Ruger HA, Bussenius CE, translators). New York: Dover.

Erber J (1976) Retrograde amnesia in honeybees (Apis mellifera carnica). J Comp Physiol Psychol 90:41-46.

Fanselow MS (1980) Conditioned and unconditional components of postshock freezing. Pavlov J Biol Sci 15:177-182.

Folkers E, Drain P, Quinn WG (1993) Radish, a Drosophila mutant deficient in consolidated memory. Proc Natl Acad Sci USA 90:8123-8127.

Folkers E, Waddell S, Quinn WG (2006) The Drosophila radish gene encodes a protein required for anesthesia-resistant memory. Proc Natl Acad Sci USA 103:17496-17500.

Frey U, Morris RG (1997) Synaptic tagging and long-term potentiation. Nature 385:533-536.

Frost WN, Castellucci VF, Hawkins RD, Kandel ER (1985) Monosynaptic connections made by the sensory neurons of the gill- and siphonwithdrawal reflex in Aplysia participate in the storage of long-term memory for sensitization. Proc Natl Acad Sci USA 82:8266-8269.

Fulton D, Kemenes I, Andrew RJ, Benjamin PR (2005) A single timewindow for protein synthesis-dependent long-term memory formation after one-trial appetitive conditioning. Eur J Neurosci 21:1347-1358.

Garcia J, KimeldorfDJ, Koelling RA (1955) Conditioned aversion to saccharin resulting from exposure to gamma radiation. Science 122:157-158.

Garcia J, Ervin FR, Yorke CH, Koelling RA (1967) Conditioning with delayed vitamin injections. Science 155:716-718

Ge X, Hannan F, Xie Z, Feng C, Tully T, Zhou H, Xie Z, Zhong Y (2004) Notch signaling in Drosophila long-term memory formation. Proc Natl Acad Sci USA 101:10172-10176.

Hanesch U, Fischbach, K.-F., and Heisenberg M (1989) Neuronal architecture of the central complex in Drosophila melanogaster. Cell Tissue Res 257:343-366.

Isabel G, Pascual A, Preat T (2004) Exclusive consolidated memory phases in Drosophila. Science 304:1024-1027.

Jaffe K (1980) Effect of cycloheximide on protein synthesis and memory in praying mantis. Physiol Behav 25:367-371.

Jiao Y, Moon SJ, Montell C (2007) A Drosophila gustatory receptor re- quired for the responses to sucrose, glucose, and maltose identified by mRNA tagging. Proc Natl Acad Sci USA 104:14110-14115.

Keene AC, Stratmann M, Keller A, Perrat PN, Vosshall LB, Waddell S (2004) Diverse odor-conditioned memories require uniquely timed dorsal paired medial neuron output. Neuron 44:521-533.

Keene AC, Krashes MJ, Leung B, Bernard JA, Waddell S (2006) Drosophila dorsal paired medial neurons provide a general mechanism for memory consolidation. Curr Biol 16:1524-1530.

Kim YC, Lee HG, Han KA (2007) D1 dopamine receptor dDA1 is required in the mushroom body neurons for aversive and appetitive learning in Drosophila. J Neurosci 27:7640-7647.

Kitamoto T (2001) Conditional modification of behavior in Drosophila by targeted expression of a temperature-sensitive shibire allele in defined neurons. J Neurobiol 47:81-92.

Krashes MJ, Keene AC, Leung B, Armstrong JD, Waddell S (2007) Sequential use of mushroom body neuron subsets during Drosophila odor memory processing. Neuron 53:103-115.

Lonze BE, Ginty DD (2002) Function and regulation of CREB family transcription factors in the nervous system. Neuron 35:605-623.

Lossner B, Rose SP (1983) Passive avoidance training increases fucokinase activity in right forebrain base of day-old chicks. J Neurochem 41:1357-1363.

Marella S, Fischler W, Kong P, Asgarian S, Rueckert E, Scott K (2006) Imaging taste responses in the fly brain reveals a functional map of taste category and behavior. Neuron 49:285-295.

Martin KC, Casadio A, Zhu H, Yaping E, Rose JC, Chen M, Bailey CH, Kandel ER (1997) Synapse-specific, long-term facilitation of aplysia sensory to motor synapses: a function for local protein synthesis in memory storage. Cell 91:927-938.

McGaugh JL (1966) Time-dependent processes in memory storage. Science 153:1351-1358

McGuire SE, Le PT, Davis RL (2001) The role of Drosophila mushroom body signaling in olfactory memory. Science 293:1330-1333.

Melcher C, Bader R, Pankratz MJ (2007) Amino acids, taste circuits, and feeding behavior in Drosophila: towards understanding the psychology of feeding in flies and man. J Endocrinol 192:467-472.

Menzel R. (2001) Searching for the memory trace in a mini-brain, the honeybee. Learn Mem 8:53-62.

Mery F, Kawecki TJ (2005) A cost of long-term memory in Drosophila. Science 308:1148.

Mizumori SJ, Rosenzweig MR, Bennett EL (1985) Long-term working memory in the rat: effects of hippocampally applied anisomycin. Behav Neurosci 99:220-232.

Montarolo PG, Goelet P, Castellucci VF, Morgan J, Kandel ER, Schacher S (1986) A critical period for macromolecular synthesis in long-term heterosynaptic facilitation in Aplysia. Science 234:1249-1254.

Perazzona B, Isabel G, Preat T, Davis RL (2004) The role of cAMP response element-binding protein in Drosophila long-term memory. J Neurosci 24:8823-8828.

Quinn WG, Dudai Y (1976) Memory phases in Drosophila. Nature 262:576-577.

Renn SC, Armstrong JD, Yang M, Wang Z, An X, Kaiser K, Taghert PH (1999) Genetic analysis of the Drosophila ellipsoid body neuropil: organization and development of the central complex. J Neurobiol 41:189-207.

Rose SP, Jork R (1987) Long-term memory formation in chicks is blocked by 2-deoxygalactose, a fucose analog. Behav Neural Biol 48:246-258.

Schafe GE, LeDoux JE (2000) Memory consolidation of auditory pavlovian fear conditioning requires protein synthesis and protein kinase $\mathrm{A}$ in the amygdala. J Neurosci 20:RC96(1-5).

Schwaerzel M, Monastirioti M, Scholz H, Friggi-Grelin F, Birman S, Heisenberg M (2003) Dopamine and octopamine differentiate between aversive and appetitive olfactory memories in Drosophila. J Neurosci 23:10495-10502.

Schwaerzel M, Jaeckel A, Mueller U (2007) Signaling at A-kinase anchoring proteins organizes anesthesia-sensitive memory in Drosophila. J Neurosci 27:1229-1233.

Si K, Giustetto M, Etkin A, Hsu R, Janisiewicz AM, Miniaci MC, Kim JH, Zhu H, Kandel ER (2003) A neuronal isoform of CPEB regulates local protein synthesis and stabilizes synapse-specific long-term facilitation in Aplysia. Cell 115:893-904. 
Slone J, Daniels J, Amrein H (2007) Sugar receptors in Drosophila. Curr Biol 17:1809-1816.

Sonderegger P, Patthy L (2007) Comment on "Tequila, a neurotrypsin ortholog, regulates long-term memory formation in Drosophila." Science 316:1698; author reply 1698 .

Strauss R, Heisenberg M (1993) A higher control center of locomotor behavior in the Drosophila brain. J Neurosci 13:1852-1861.

Sugai R, Azami S, Shiga H, Watanabe T, Sadamoto H, Kobayashi S, Hatakeyama D, Fujito Y, Lukowiak K, Ito E (2007) One-trial conditioned taste aversion in Lymnaea: good and poor performers in long-term memory acquisition. J Exp Biol 210:1225-1237.

Tempel BL, Bonini N, Dawson DR, Quinn WG (1983) Reward learning in normal and mutant Drosophila. Proc Natl Acad Sci USA 80:1482-1486.

Thorne N, Chromey C, Bray S, Amrein H (2004) Taste perception and coding in Drosophila. Curr Biol 14:1065-1079.

Thum AS, Jenett A, Ito K, Heisenberg M, Tanimoto H (2007) Multiple memory traces for olfactory reward learning in Drosophila. J Neurosci 27:11132-11138.

Tully T, Quinn WG (1985) Classical conditioning and retention in normal and mutant Drosophila melanogaster. J Comp Physiol A Neuroethol Sens Neural Behav Physiol 157:263-277.
Tully T, Preat T, Boynton SC, Del Vecchio M (1994) Genetic dissection of consolidated memory in Drosophila. Cell 79:35-47.

Waddell S, Armstrong JD, Kitamoto T, Kaiser K, Quinn WG (2000) The amnesiac gene product is expressed in two neurons in the Drosophila brain that are critical for memory. Cell 103:805-813.

Wang Z, Singhvi A, Kong P, Scott K (2004) Taste representations in the Drosophila brain. Cell 117:981-991.

Wu CL, Xia S, Fu TF, Wang H, Chen YH, Leong D, Chiang AS, Tully T (2007) Specific requirement of NMDA receptors for long-term memory consolidation in Drosophila ellipsoid body. Nat Neurosci 10:1578-1586.

Yin JC, Wallach JS, Del VM, Wilder EL, Zhou H, Quinn WG, Tully T (1994) Induction of a dominant negative CREB transgene specifically blocks long-term memory in Drosophila. Cell 79:49-58.

Yu D, Keene AC, Srivatsan A, Waddell S, Davis RL (2005) Drosophila DPM neurons form a delayed and branch-specific memory trace after olfactory classical conditioning. Cell 123:945-957.

Yu D, Akalal DB, Davis RL (2006) Drosophila alpha/beta mushroom body neurons form a branch-specific, long-term cellular memory trace after spaced olfactory conditioning. Neuron 52:845-855.

Zars T, Fischer M, Schulz R, Heisenberg M (2000) Localization of a shortterm memory in Drosophila. Science 288:672-675. 